\title{
ZONEAMENTO ACROCLIMÁTICO PARA O CULTIVO DO ABACAXI NO ESPÍRITO SANTO MEDIANTE INTERPOLAÇÃO ESPACIAL
}

\section{Nathália Aparecida Bragança Fávaris ${ }^{1}$ \\ Alixelhe Pacheco Damascena² \\ Natália Zardo Barbiero ${ }^{3}$}

Resumo: No Brasil, o abacaxizeiro é uma frutífera de ampla distribuição no território nacional ocupando a sexta posição como a fruta mais produzida no país. Objetivou-se, com este estudo, propor a determinação do Zoneamento Agroclimático do Ananas comosus L. mediante a utilização de interpolação espacial para o estado do Espírito Santo. As etapas metodológicas necessárias para avaliar o zoneamento foram: geração do banco de dados e interpolação espacial. Os resultados mostraram que o Espírito Santo possui 73,77\% de suas áreas aptas ao cultivo, 21,76\% restritas e 4,48\% de suas áreas inaptas ao cultivo do abacaxizeiro. Palavras-chave: Ananas comosus; Clima; Temperatura.

\footnotetext{
${ }^{1}$ Agronomia/Universidade Federal do Espírito Santo, Brasil. E-mail: nath-braganca@hotmail.com.

2 Agronomia/Universidade Federal do Espírito Santo, Brasil. E-mail: xellydamasceno@hotmail.com.

${ }^{3}$ Agronomia/Universidade Federal do Espírito Santo, Brasil. E-mail: natalia.zardo@hotmail.com.
} 